\title{
End-of-life care in oxygen-dependent ILD compared with lung cancer: a national population-based study
}

\author{
Zainab Ahmadi, ${ }^{1}$ Nicholas G Wysham, ${ }^{2}$ Staffan Lundström, ${ }^{3}$ Christer Janson, ${ }^{4}$ \\ David C Currow, ${ }^{5}$ Magnus Ekström ${ }^{1,5}$
}

- Additional material is published online only. To view please visit the journal online (http://dx.doi.org/10.1136/ thoraxjn-2015-207439)

For numbered affiliations see end of article.

\section{Correspondence to} Dr Zainab Ahmadi, Division of Respiratory Medicine \& Allergology, Department of Clinical Sciences, Lund University Hospital, Lund SE-221 00, Sweden; zai.ahmd@gmail.com

Received 15 June 2015 Revised 27 December 2015

Accepted 3 January 2016 Published Online First 10 February 2016
CrossMark

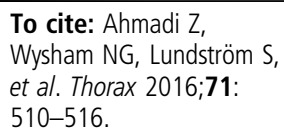

\section{ABSTRACT}

Rationale Advanced fibrosing interstitial lung disease (ILD) is often progressive and associated with a high burden of symptoms and poor prognosis. Little is known about the symptom prevalence and access to palliative care services at end of life (EOL).

Objectives Compare prevalence of symptoms and palliative treatments between patients dying with oxygen-dependent ILD and patients dying of lung cancer.

Methods Nationwide registry-based cohort study of patients with oxygen-dependent ILD and patients with lung cancer who died between 1 January 2011 and 14 October 2013. Prevalence of symptoms and treatments during the last seven days of life were compared using data in Swedish Registry of Palliative Care.

Measurements and main results 285 patients with ILD and 10822 with lung cancer were included. In ILD, death was more likely to be 'unexpected' (15\% vs $4 \%$ ), less likely to occur in a palliative care setting $(17 \%$ vs $40 \%$ ) and EOL discussions with the patients (41\% vs $59 \%$ ) were less common than in lung cancer. Patients with ILD suffered more from breathlessness ( $75 \%$ vs $42 \%)$ while patients with lung cancer had more pain $(51 \%$ vs $73 \%)$ ( $p<0.005$ for all comparisons). Patients with ILD had more unrelieved breathlessness, pain and anxiety. The survival time from initiation of oxygen therapy in ILD was a median 8.4 months (IQR 3.419.2 months).

Conclusions Patients with ILD receive poorer access to specialist EOL care services and experience more breathlessness than patients with lung cancer. This study highlights the need of better EOL care in oxygendependent ILD.

\section{INTRODUCTION}

Advanced fibrosing interstitial lung disease (ILD) is a group of often progressive and incurable conditions. ${ }^{12}$ The most common form of ILD, idiopathic pulmonary fibrosis (IPF), is associated with poor survival, and high symptom burden and poor quality of life as the disease progresses. ${ }^{2-5}$ ILD represents an increasing proportion of patients with chronic hypoxemic respiratory failure. ${ }^{6}$ There are no prevalence figures of IPF available in Sweden, but the rate probably approximates that of our neighbouring country, Finland, with 14-16/ 100000 inhabitants. $^{7}$

Despite this poor prognosis, palliative care remains underused in patients with ILD. ${ }^{8}$ This may be due to under-recognition of the palliative care

\section{Key messages}

What is the key question?

- What is the quality of end-of-life care for patients dying with oxygen-dependent interstitial lung disease?

\section{What is the bottom line?}

- Patients dying with interstitial lung disease frequently suffer from breathlessness and receive suboptimal end-of-life care across multiple domains.

\section{Why read on?}

- The end-of-life needs for patients with interstitial lung disease have not been systematically described.

needs and symptom burden, or unfamiliarity and discomfort with palliative therapies. ${ }^{9}$ Though oncology has largely embraced earlier integration of palliative care, which has translated into improvements in end-of-life (EOL) care for patients with lung cancer, ${ }^{10}$ palliative and EOL care for non-malignant diseases are now gaining increased attention. In pulmonary disease, this research has mainly focused on COPD and demonstrated a significant burden of unmet palliative care needs and lower quality of EOL care compared with patients with cancer. ${ }^{11-13}$ Similar attention is only beginning to be paid to ILD, ${ }^{8}{ }^{14-16}$ but symptom burden and quality of EOL care in patients with ILD have yet to be quantified.

The aim of this study was to determine the period prevalence of symptoms during the last week of life and characterise their management at EOL in patients with oxygen-dependent ILD compared with terminal lung cancer. In making this comparison, we hope to highlight ways to improve the EOL care for patients with oxygen-dependent ILD.

\section{MATERIALS AND METHODS}

This was a nationwide registry-based cohort study including all patients starting long-term oxygen therapy (LTOT) for physician-diagnosed ILD in the Swedevox registry who died between 1 January 2011 and 14 October 2013. A previous analysis indicates that most patients suffered from IPF, ${ }^{17}$ so 
we have chosen to use the more inclusive and more accurate term fibrotic ILD. Analyses were carried out using the Swedish Registry of Palliative Care (SRPC) and including patients with ILD from Swedevox. The physiological data of patients with ILD at time of initiation of LTOT from Swedevox data were cross-linked with SRPC data on the last seven days of life using each patient's unique Swedish identification number.

Data on patients with oxygen-dependent ILD were compared with data from patients on the SRPC who died from lung cancer in the same time period. Lung cancer was identified using the tenth revision of the International Classification of Disease (ICD-10) by cross-linking SRPC data on cancer patients with Causes of Death Registry. ICD-10 code C34 for lung cancer as either underlying cause or the first five contributing causes of death was identified and included in the comparator group.

\section{Swedevox}

The Swedevox registry prospectively includes patients starting LTOT in Sweden with a population-based coverage of about $85 \% .{ }^{18-20}$ It contains patients' diagnosis requiring LTOT and physiological data including arterial blood gas tensions when breathing air and oxygen, body mass index (BMI) and $\mathrm{FEV}_{1}$ registered at the start of LTOT. Accuracy of ILD diagnosis in this registry has been previously validated. ${ }^{17}$ Details of the registry are described elsewhere. ${ }^{21}$

\section{The SRPC}

The SRPC is a national quality register of the care of patients during their last week of life regardless of place of care or diagnosis. $^{22}{ }^{23}$ During 2013, 87\% of all deaths from cancer nationwide were included in the registry. ${ }^{24}$ SRPC contains data on the presence of breathlessness, pain, death rattle, nausea, anxiety and confusion during the last seven days of life and prevalence of provided treatment of 'as needed' medications for pain, nausea, anxiety and death rattle at least one day before death. ${ }^{22}$

The SRPC collects data through an EOL questionnaire completed retrospectively by the responsible nurse and/or physician within a week of the patient's death; all deaths are expected to be registered, irrespective of place of death, diagnosis, age or involvement of formalised palliative care. The report is based on the patient record and recall of the care that may not have been documented, preferably after a team discussion so as to include the experience of all team members. ${ }^{22}$ The version of the questionnaire that was used to collect data was launched in January 2011 (see online supplementary material for an English version of the questionnaire). The questionnaire is completed online and all questions must be answered before submission. A previous study supported the validity of the questionnaire. ${ }^{25}$

\section{Assessments}

The period prevalence was estimated for each symptom from responses to the question, "Were any of the following symptoms prevalent at some time during the last week of life?" (yes or no). For any reported symptom, symptom relief was graded as relieved, partially relieved or unrelieved.

Prevalence of 'as needed' medication prescriptions was analysed among symptomatic patients for each identified symptom in response to the question, "Was medication prescribed for use as needed in the form of injections before death for pain, death rattle, nausea and anxiety?" (yes or no). This reflects prescription of medication, not necessarily administered doses.

\section{Statistical analyses}

Baseline characteristics were summarised using standard descriptive statistics. The differences among the groups were tested with $t$ test for continuous and $\chi^{2}$ test for categorical variables. Multivariate logistic regression was carried out adjusting for age at death and gender. Statistical significance was defined as a double-sided $\mathrm{p}<0.05$. Statistical analyses were conducted using the software packages Stata, V.12 (StataCorp; College Station, Texas, USA).

\section{RESULTS}

Of an initial 490 patients with ILD in Swedevox who died between 1 January 2011 and 14 October 2013, 285 (58\%) were registered in SRPC and included in the study (figure 1). Characteristics were similar between patients with LTOT who were and were not included in terms of age, sex, lung function, BMI and arterial blood gas levels (see online supplementary material table E1).

In the SRPC, 10822 patients died from lung cancer during the same time period and were included in the analysis as the comparator group. Characteristics of the patients with ILD and lung cancer are shown in table 1 . Compared with patients with lung cancer, patients with ILD were slightly older $(78 \pm 8$ vs 73 \pm 10 years) and a smaller percentage were women (39\% vs $48 \%$ ). The survival time from initiation of LTOT was a median 8.4 months (IQR 3.4-19.2 months) (figure 2).

EOL care for patients with oxygen-dependent ILD had less palliative care input on nearly every measure (table 2). In ILD, death was more likely to be unexpected (15\% vs $4 \%)$, less likely to occur in a palliative care setting (17\% vs $40 \%)$ and there were fewer EOL discussions with the patients ( $41 \%$ vs $59 \%)$ and families (52\% vs $73 \%)$. Validated symptom scales were used
Figure 1 Flow chart of study population selection. ILD, interstitial lung disease; LTOT, long-term oxygen therapy; SRPC, Swedish Registry of Palliative Care.
ILD cohort

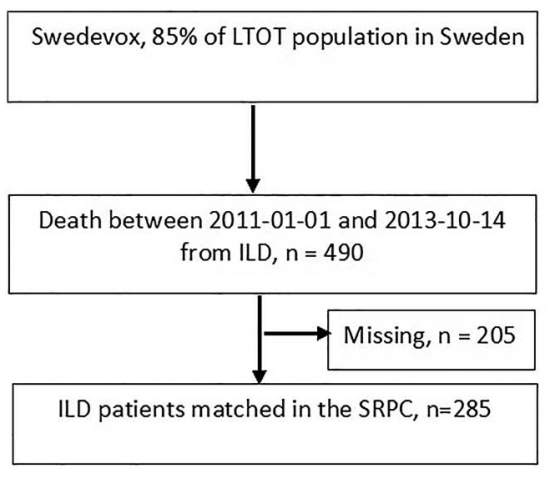

Lung cancer cohort

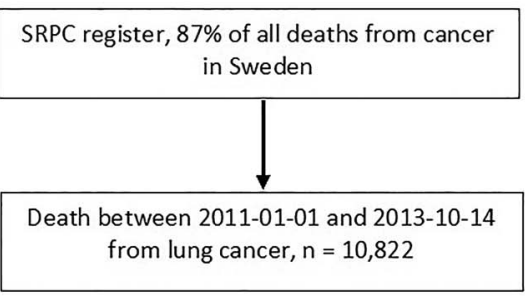


Table 1 Baseline patient characteristics in patients with oxygen-dependent interstitial lung disease (ILD) versus lung cancer

\begin{tabular}{lll}
\hline Characteristic & $\begin{array}{l}\text { ILD } \\
\mathbf{n}=\mathbf{2 8 5}\end{array}$ & $\begin{array}{l}\text { Lung cancer } \\
\mathbf{n}=10822\end{array}$ \\
\hline Age, years (at death) & $78.2 \pm 8$ & $72.9 \pm 10$ \\
Female, $\mathrm{n}(\%)$ & $112(39)$ & $5233(48)$ \\
$\mathrm{FEV}_{1}, \mathrm{~L}$ & $1.58 \pm 0.6$ & - \\
$\mathrm{FEV}_{1} \%$ pred* & $60(50-80)$ & - \\
$\mathrm{BMI}^{*} \mathrm{~kg} / \mathrm{m}^{2}$ & $25.1 \pm 4.8$ & - \\
$\mathrm{PaO}_{2}$ breathing air, $\mathrm{kPa}$ & $6.6 \pm 1.1$ & - \\
$\mathrm{PaCO}_{2}$ breathing air, $\mathrm{kPa}$ & $5.0 \pm 0.9$ & - \\
\hline
\end{tabular}

Data presented as mean \pm SD unless otherwise specified.

${ }^{*}$ Median (first quartile- -third quartile).

$\mathrm{BMI}$, body mass index; $\mathrm{FEV}_{1} \%$ pred, $\mathrm{FEV}_{1}$ of predicted value, percentage; $\mathrm{PaO}_{2}$ (air), arterial blood gas tension of oxygen on air; $\mathrm{PaCO}_{2}$ (air), arterial blood gas tension of carbon dioxide on air.

less frequently in patients with ILD for pain $(13 \%$ vs $28 \%$, $\mathrm{p}<0.001)$ and for other symptoms ( $8 \%$ vs $14 \%, \mathrm{p}=0.004)$. Patients with ILD also had significantly greater period prevalence of breathlessness ( $75 \%$ vs $42 \%)$ than patients with lung cancer (table 3). In contrast, pain, death rattle and confusion were more common among patients with lung cancer. Nausea, and especially anxiety, was common, but similar between groups. Figure 3 illustrates symptom prevalence in both groups. Notably, there was a high rate of responding 'don't know' to the presence of many symptoms, higher in the ILD group for all symptoms (see online supplementary material table E2). For example, $21 \%$ of patients dying with ILD did not have the presence of breathlessness ascertained compared with $9 \%$ for lung cancer.

The prevalence of relieved and unrelieved symptoms is shown in table 4. Patients with ILD had lower rates of complete relief from breathlessness $(17 \%$ vs $33 \%, \mathrm{p}<0.001)$. Complete relief of pain $(62 \%$ vs $70 \%, \mathrm{p}=0.169)$ and anxiety $(52 \%$ vs $55 \%$, $\mathrm{p}=0.480$ ) was similar (figure 4). Patients with ILD were less frequently prescribed as needed medications for death rattle $(77 \%$ vs $88 \%)$, pain ( $83 \%$ vs 96$)$, anxiety $(79 \%$ vs $91 \%)$ and nausea (51\% vs $73 \%) ; \mathrm{p}<0.001$ for all comparisons (table 5). An alternative analysis of the prescription data limited to patients who were symptomatic shows a similar result (see online supplementary material table E3). For example, $92 \%$ of patients

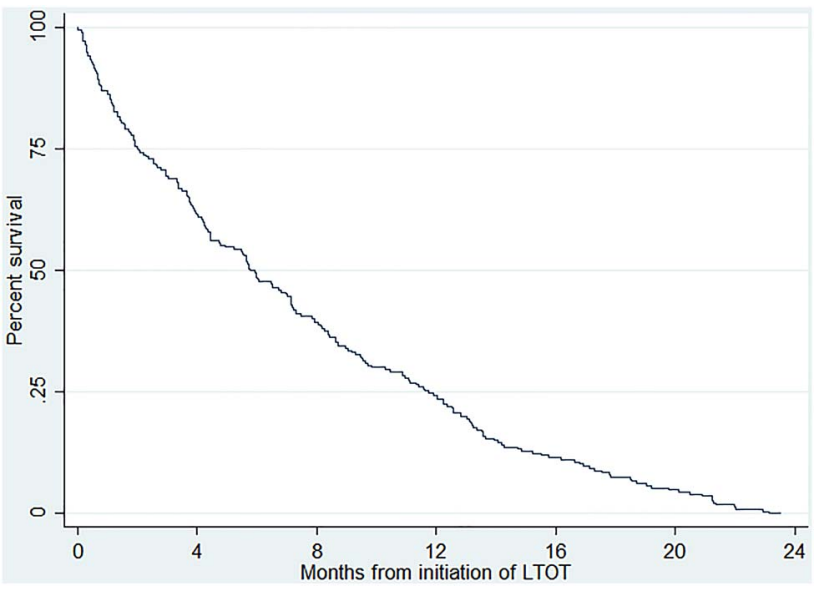

Figure 2 Kaplan-Meier survival curve in 285 patients with oxygen-dependent interstitial lung disease. LTOT, long-term oxygen therapy.
Table 2 End-of-life (EOL) care in patients with oxygen-dependent interstitial lung disease (ILD) versus lung cancer

\begin{tabular}{|c|c|c|c|}
\hline & $\begin{array}{l}\text { ILD } \\
n=285\end{array}$ & $\begin{array}{l}\text { Lung } \\
\text { cancer } \\
n=10822\end{array}$ & $\begin{array}{l}p \text { Value } \\
\left(\chi^{2} \text { test }\right)\end{array}$ \\
\hline \multicolumn{4}{|l|}{ Expected death } \\
\hline Unexpected & $41(15)$ & $454(4)$ & $<0.001$ \\
\hline Expected & $235(82)$ & $10205(94)$ & $<0.001$ \\
\hline Unknown & $9(3)$ & $163(2)$ & 0.026 \\
\hline \multicolumn{4}{|l|}{ Place of death } \\
\hline Hospice/palliative hospital ward & $23(8)$ & $2988(27)$ & $<0.001$ \\
\hline Hospital ward, not palliative & $130(46)$ & $3964(37)$ & 0.098 \\
\hline Nursing home & $50(17)$ & $746(7)$ & $<0.001$ \\
\hline Specialised palliative home care & $26(9)$ & $1421(13)$ & 0.001 \\
\hline General palliative home care & $27(10)$ & $529(5)$ & 0.025 \\
\hline Short-term care home & $25(9)$ & $1108(10)$ & 0.010 \\
\hline Other & $4(1)$ & $66(1)$ & 0.254 \\
\hline EOL discussion with patient & $117(41)$ & $6337(59)$ & $<0.001$ \\
\hline EOL discussion with family & $148(52)$ & $7923(73)$ & $<0.001$ \\
\hline Died in preferred place of death & $116(41)$ & $5166(48)$ & 0.019 \\
\hline Palliative care team consultation & $14(6)$ & $1215(19)$ & 0.655 \\
\hline Next of kin present at death & $98(34)$ & $4532(42)$ & 0.006 \\
\hline Use of validated symptom scale for pain & $38(13)$ & $3024(28)$ & $<0.001$ \\
\hline $\begin{array}{l}\text { Use of validated symptom scale for other } \\
\text { symptoms }\end{array}$ & $23(8)$ & $1518(14)$ & 0.004 \\
\hline $\begin{array}{l}\text { Use of parenteral fluids/nutrition during } \\
\text { the last day }\end{array}$ & $41(14)$ & $1526(14)$ & 0.891 \\
\hline
\end{tabular}

with symptomatic ILD were prescribed as-needed medications for pain compared with $98 \%$ of patients with lung cancer $(\mathrm{p}<0.001)$. Treatment for breathlessness was not separately recorded.

The OR for breathlessness was more than three times higher for ILD compared with lung cancer (OR 3.49; CI 2.57 to 4.73), and the symptom ORs were similar adjusting for age and gender (table 6).

\section{DISCUSSION}

\section{Key findings}

The present study suggests that patients dying with oxygendependent ILD receive lower quality EOL care and experience

Table 3 Prevalence of symptoms at end-of-life (EOL) in patients with oxygen-dependent interstitial lung disease (ILD) versus lung cancer

\begin{tabular}{|c|c|c|c|c|c|}
\hline $\begin{array}{l}\text { Experienced } \\
\text { symptom }\end{array}$ & Total $\mathbf{n}$ & $\begin{array}{l}\text { ILD } \\
\mathrm{n}(\%)\end{array}$ & Total $\mathbf{n}$ & $\begin{array}{l}\text { Lung } \\
\text { cancer } \\
\text { n (\%) }\end{array}$ & $\begin{array}{l}\mathrm{p} \text { Value } \\
\left(\chi^{2} \text { test }\right)\end{array}$ \\
\hline Breathlessness & 226 & $170(75)$ & 9855 & $4586(42)$ & $<0.001$ \\
\hline Death rattle & 236 & $102(43)$ & 10128 & $6318(63)$ & $<0.001$ \\
\hline Pain & 228 & $117(51)$ & 10038 & 7812 (73) & $<0.001$ \\
\hline Anxiety & 208 & $138(66)$ & 9346 & $5882(63)$ & 0.314 \\
\hline Nausea & 219 & 31 (14) & 9343 & 1497 (16) & 0.456 \\
\hline Confusion & 210 & $41(20)$ & 9291 & $2948(32)$ & $<0.001$ \\
\hline \multicolumn{6}{|c|}{$\begin{array}{l}\text { Patients with oxygen-dependent ILD ( } n=285 \text { ) or lung cancer ( } n=10822) \text {. The } \\
\text { prevalence }(\%) \text { of symptoms during the last week of life: patients whose medical } \\
\text { team answered 'yes' to the presence of a particular symptom as a percentage of the } \\
\text { 'total } n \text { ' who answered 'yes' or 'no' to the question. 'Don't know' was the other } \\
\text { possible answer, and these were excluded, accounting for the different } n \text { for each } \\
\text { symptom. }\end{array}$} \\
\hline
\end{tabular}




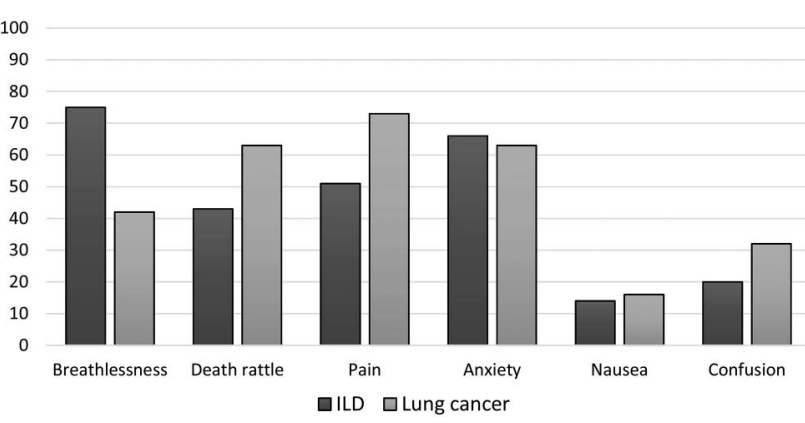

Figure 3 Prevalence (\%) of symptoms in interstitial lung disease (ILD) $(n=285)$ compared with lung cancer $(n=10822)$ at end of life in Sweden.

more breathlessness compared with patients dying of lung cancer.

To our knowledge, this is the first population-based study documenting symptom prevalence at the EOL using quantitative methods in people with ILD. Our findings are made more representative and robust due to its population-based and multicentre design. The other similar study of this size was single centre and could not include symptom prevalence. ${ }^{8}$ Furthermore, they included patients seen over many years in order to amass such numbers, and so their results may be less descriptive of current practices.

Our findings are consistent with other studies reporting underutilisation of specialised palliative care services in ILD. ${ }^{9}{ }^{16}$ Underuse of specialised palliative care may lead to under-recognition of symptom burden and palliative care needs.

Table 4 Prevalence of symptom relief at end-of-life (EOL) in patients with oxygen-dependent interstitial lung disease (ILD) versus lung cancer

\begin{tabular}{|c|c|c|c|c|c|}
\hline \multirow[b]{2}{*}{ Experienced symptom } & \multicolumn{2}{|l|}{ ILD } & \multicolumn{2}{|c|}{ Lung cancer } & \multirow{2}{*}{$\begin{array}{l}p \text { Value } \\
\left(\chi^{2} \text { test }\right)\end{array}$} \\
\hline & Total $\mathrm{n}$ & $n(\%)$ & Total $n$ & n (\%) & \\
\hline Breathlessness & 170 & & 4586 & & \\
\hline Relieved & & 30 (17) & & $1528(33)$ & $<0.001$ \\
\hline Partially relieved & & $132(78)$ & & $2913(64)$ & $<0.001$ \\
\hline Unrelieved & & $8(5)$ & & $145(3)$ & 0.263 \\
\hline Death rattle & 102 & & 6318 & & \\
\hline Relieved & & 37 (36) & & 2490 (39) & 0.520 \\
\hline Partially relieved & & $60(59)$ & & 3484 (55) & 0.459 \\
\hline Unrelieved & & $5(5)$ & & $344(6)$ & 0.810 \\
\hline Pain & 117 & & 7812 & & \\
\hline Relieved & & $74(62)$ & & $5403(70)$ & 0.169 \\
\hline Partially relieved & & $42(35)$ & & $2376(31)$ & 0.201 \\
\hline Unrelieved & & $1(1)$ & & $33(1)$ & 0.478 \\
\hline Anxiety & 138 & & 5882 & & \\
\hline Relieved & & $72(52)$ & & 3247 (55) & 0.480 \\
\hline Partially relieved & & $64(47)$ & & $2588(44)$ & 0.578 \\
\hline Unrelieved & & $2(1)$ & & $47(1)$ & 0.401 \\
\hline Nausea & 31 & & 1497 & & \\
\hline Relieved & & $16(52)$ & & $821(55)$ & 0.721 \\
\hline Partially relieved & & $14(45)$ & & $636(42)$ & 0.765 \\
\hline Unrelieved & & $1(3)$ & & $40(3)$ & 0.850 \\
\hline Confusion & 41 & & 2948 & & \\
\hline Relieved & & $7(17)$ & & $524(18)$ & 0.907 \\
\hline Partially relieved & & $29(71)$ & & $1818(62)$ & 0.236 \\
\hline Unrelieved & & $5(12)$ & & $606(20)$ & 0.187 \\
\hline
\end{tabular}

Patients with oxygen-dependent ILD ( $n=285)$ or lung cancer $(n=10$ 822). Figures are numbers (percentage) unless stated otherwise.
Our data support this hypothesis in demonstrating a lower use of structured symptom assessments at EOL among patients with ILD.

While patients with lung cancer also suffer a high burden of symptoms at the EOL-particularly pain, death rattle and confusion-the frequency of complete relief of all symptoms met or exceeded that in ILD. This is likely explained in part by a greater rate of use of as-needed medications directed at all symptoms. Also, more frequent use of validated instruments for symptom assessment in cancer, and hence greater attention to distressing symptoms, could in part explain these differences. While not every symptom can or (depending on patient goals) should be completely relieved, these disparities suggest a quality issue in the provision of EOL care for ILD.

One explanation for our findings may be that pulmonologists are uncertain when and how to involve palliative care in advanced ILD. Though all recognise that ILD is progressive, the terminal decline often seems sudden or unpredictable, resulting in late referral to palliative care. ${ }^{8}$ Our data demonstrate a fairly rapid decline towards death in oxygen-depending ILD patients with a median survival time of 8.4 months after starting LTOT. This supports that referral to specialised palliative care should be offered when starting LTOT, if not earlier, and that palliative care services should be made available on an outpatient basis. A more proactive palliative approach may allow patients to avoid hospital admission at the EOL if that is consistent with the patients' wishes.

Along these lines, some of the observed differences between these groups may be related to these disease-specific factors. For instance, perhaps the terminal decline in ILD is more sudden than in lung cancer and more difficult to predict. This may necessitate a higher frequency of hospital admission at the EOL, perhaps for acute symptom management. Still, even hospitalised patients with ILD had lower access of palliative care services.

Another potential explanation for the higher symptom burden in ILD may be that pulmonologists are unfamiliar or uncomfortable with palliative therapies in chronic respiratory failure. Breathlessness is the most prevalent symptom at EOL by far, yet studies have shown systematic under-recognition of breathlessness ${ }^{26} 27$ and unfamiliarity and discomfort with palliative care therapies for breathlessness. ${ }^{28} 29$ Some have described a therapeutic nihilism in treating breathlessness. ${ }^{30}$ Along similar lines, our data suggest that pain and anxiety are nearly as prevalent as breathlessness for patients with ILD at the EOL, arguing for a comprehensive assessment of palliative care needs.

Interestingly, the symptom burden and the poor quality of EOL care in ILD appears to be similar to COPD. ${ }^{31}$ Point estimates of nearly all measures for ILD are similar to a prior study of COPD using the same data sources. ${ }^{32}$ EOL care and symptom burden at EOL among non-malignant lung diseases are currently similar and inferior to the care provided to patients dying of cancer. Models for integration of respiratory and palliative care are emerging for COPD, ${ }^{33}$ and it is likely that patients with ILD will benefit from similar care models.

\section{STRENGTHS AND LIMITATIONS}

Strengths of the present study include its national, populationbased design and inclusion of the largest cohort to date of patients with ILD on LTOT and lung cancer. No previous studies have included the very last days of life among patients with ILD or used quantitative measures to report symptom prevalence. These features enhance the generalisability and interpretation of our findings. 
ILD

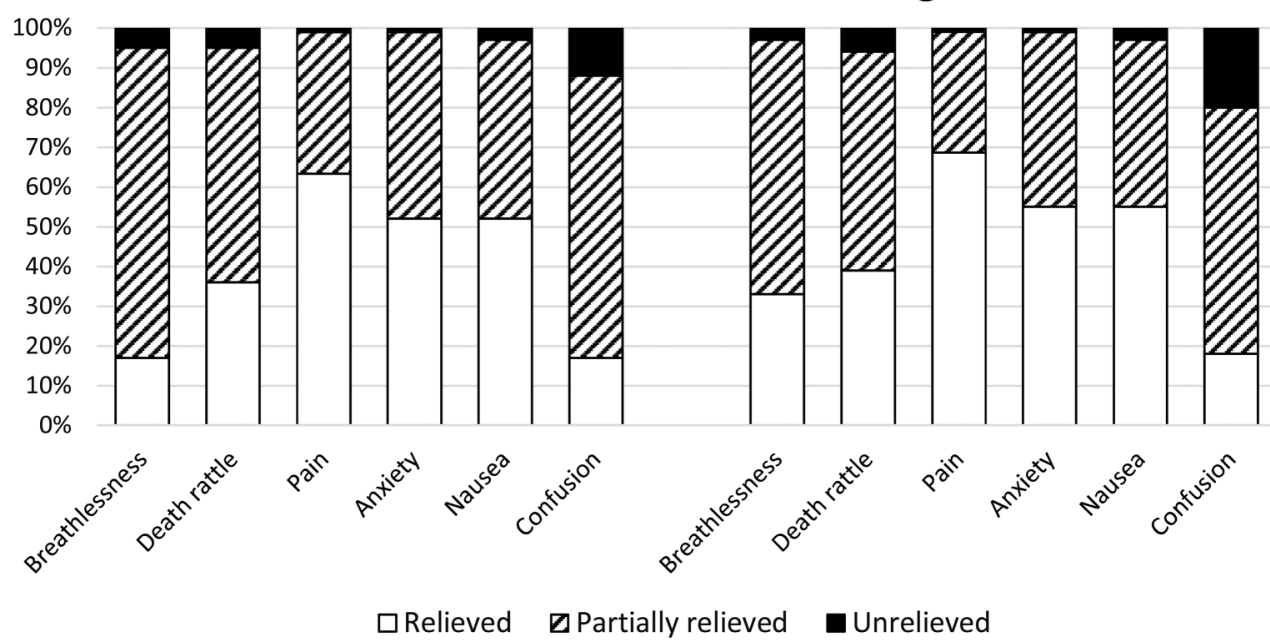

Figure 4 Symptom management with prevalence (\%) of relieved, partially relieved and unrelieved symptoms in interstitial lung disease (ILD) $(n=285)$ compared with lung cancer $(n=10822)$ at end of life in Sweden.

Possible limitations of our study include that data on palliative care in SRPC were, by design, collected retrospectively. The questionnaire was answered by staff, which could be influenced by recall bias and social desirability bias, but it is unknown whether these biases would apply differentially to patients with ILD or cancer. Staff proxy assessments of symptoms in patients with advanced disease have been shown to be a valid alternative to patient self-report, especially for the detection of breathlessness. This was shown in patients with mostly cancer, and the validity of proxy reports in ILD has not yet been established. ${ }^{34}$

Another limitation is that the aetiology of ILD could be heterogeneous because our data did not allow further characterisation. It is, however, often difficult to obtain a specific diagnosis in patients with advanced ILD in the clinic. A previous study using the same data set supported the validity of the ILD diagnoses by having respiratory physicians using medical records, including available radiographic and histological data, and they found that most had IPF (according to the guidelines at that time). ${ }^{17}$ IPF is the most common fibrotic ILD, and it is associated with a high risk of progression to hypoxemic respiratory failure and death. Thus, the prevalence of IPF is most likely to be high in our sample of oxygen-dependent ILD. Furthermore, we expect the prognosis, symptom burden and care requirements between the various ILDs are likely to be more similar than different once these patients reach an oxygen-dependent stage.

Table 5 Prevalence of 'as needed' medication prescriptions at end-of-life (EOL) in patients with oxygen-dependent interstitial lung disease (ILD) versus lung cancer

\begin{tabular}{|c|c|c|c|c|c|}
\hline \multirow{2}{*}{$\begin{array}{l}\text { 'As needed' } \\
\text { prescription }\end{array}$} & \multicolumn{2}{|l|}{ ILD } & \multicolumn{2}{|c|}{ Lung cancer } & \multirow{2}{*}{$\begin{array}{l}\text { p Value } \\
\left(\chi^{2} \text { test }\right)\end{array}$} \\
\hline & Total $\mathbf{n}$ & n (\%) & Total $\mathbf{n}$ & n (\%) & \\
\hline Death rattle & 243 & $188(77)$ & 10247 & 9034 (88) & $<0.001$ \\
\hline Pain & 242 & $200(83)$ & 10293 & $9830(96)$ & $<0.001$ \\
\hline Anxiety & 239 & $189(79)$ & 10262 & 9297 (91) & $<0.001$ \\
\hline Nausea & 239 & $122(51)$ & 10176 & 7471 (73) & $<0.001$ \\
\hline
\end{tabular}

Our data were also limited by some degree of missingness. Though all survey items were required before submission, the symptom assessments allowed a response of 'don't know', which was significantly higher in the ILD group for all symptoms. In light of this, the symptom prevalence data should be interpreted with caution as missingness of survey data is often non-random and the pattern may be informative. We are unable to determine whether a response of 'don't know' is more likely to be associated with symptom presence, or absence, and so may bias the prevalence estimates in uncertain ways. The reason for this differential missingness, though, may be explained by our main observation; that patients dying with ILD receive less palliative care, and this item may reflect less attention to symptom assessment and management.

\section{Implications for practice}

Though our analysis is limited to the EOL phase of care and suggests improvements in EOL care, the outcomes we describe have implications for care leading up to EOL as well. Our findings highlight the need to improve management of patients with oxygen-dependent ILD at an early phase, perhaps when starting LTOT, by better integrating respiratory and palliative care and improving access to specialised palliative care. Our data suggest poor advance care planning with nearly half of patients with ILD dying in the hospital, a rate that is nearly double that in cancer.

Table 6 Odds of symptoms at end-of-life (EOL) in patients with oxygen-dependent interstitial lung disease (ILD) versus lung cancer

\begin{tabular}{|c|c|c|}
\hline Experienced symptom & $\begin{array}{l}\text { ILD vs lung cancer, } \\
\text { crude } \\
\text { OR }(95 \% \mathrm{CI})\end{array}$ & $\begin{array}{l}\text { ILD vs lung cancer, } \\
\text { adjusted } \\
\text { OR }(95 \% \mathrm{Cl})\end{array}$ \\
\hline Breathlessness & 3.49 (2.57 to 4.73$)$ & 3.75 (2.76 to 5.09$)$ \\
\hline Death rattle & $0.46(0.35$ to 0.60$)$ & $0.48(0.37$ to 0.62$)$ \\
\hline Pain & $0.30(0.23$ to 0.39$)$ & $0.33(0.25$ to 0.43$)$ \\
\hline Anxiety & $1.16(087$ to 1.55$)$ & $1.32(0.98$ to 1.77$)$ \\
\hline Nausea & $0.86(0.59$ to 1.27$)$ & $0.92(0.62$ to 1.35$)$ \\
\hline Confusion & $0.52(0.37$ to 0.74$)$ & $0.51(0.36$ to 0.73$)$ \\
\hline
\end{tabular}


We believe better recognition of symptom burden for patients with oxygen-dependent ILD, perhaps through use of structured symptom assessments earlier in the disease course, could discover under-recognised palliative care needs. This could then lead to improved treatment of symptoms, advance care planning and proactive referral to specialised palliative care.

Improved palliative care for patients with ILD would likely improve symptom burden, but also the other equally important domains of palliative care including psychosocial and spiritual support for patient and carers. ${ }^{35}$ While we uncovered disparities in symptom burden, patients with ILD experienced lower quality of EOL care in multiple domains. As others have advocated, this patient population would benefit from comprehensive palliative care needs tools similar to those employed in cancer. ${ }^{36} 37$

\section{CONCLUSION}

Patients with ILD have less access to palliative care services and experience more breathlessness at the EOL than patients with terminal lung cancer. Further research is needed to elucidate the care structures, processes and evidence-based therapies that optimise palliative and EOL care for ILD and other advanced, nonmalignant pulmonary diseases.

\section{Author affiliations \\ ${ }^{1}$ Division of Respiratory Medicine \& Allergology, Department of Clinical Sciences, Lund University Hospital, Lund, Sweden \\ ${ }^{2}$ Division of Pulmonary, Allergy, and Critical Care, Department of Medicine, Duke University, Center for Learning Health Care, Duke Clinical Research Institute, Durham, North Carolina, USA \\ ${ }^{3}$ Palliative Care Services, Stockholms Sjukhem Foundation, Stockholm, Sweden ${ }^{4}$ Department of Medical Sciences, Respiratory Medicine \& Allergology, Uppsala University, Uppsala, Sweden \\ ${ }^{5}$ Department of Discipline, Palliative and Supportive Services, Flinders University, Adelaide, South Australia, Australia}

Acknowledgements The analysis was carried out at the Department of Respiratory Medicine, Blekinge Hospital Karlskrona and Lund University, Sweden. The authors thank all the physicians and nurses who collected the data and cared for the patients.

Contributors ME had full access to all the data in the study and takes full responsibility for the integrity of the data and the accuracy of the data analysis. Conception and design: NGW, ME and ZA; data acquisition: ME, SL and ZA; data analysis: ME and ZA; interpretation of data: CJ, DCC, ME, NGW, SL and ZA; drafting the article: NGW, ME and ZA; revision for important intellectual content: $C J, D C C$, ME, NGW, SL and ZA; approval of the version to be published: CJ, DCC, ME, NGW, $S L$ and ZA.

Funding This study was funded by The Swedish Society of Medicine, the Swedish Respiratory Society, the Swedish Heart-Lung Foundation, the Scientific Committee of Blekinge County Council and the Wera and Emil Cornell Foundation.

Competing interests None declared.

Ethics approval Ethics committee at the Department of Medical Ethics at Lund University, Lund, Sweden (reference number LundDNr: 2013/379).

Provenance and peer review Not commissioned; externally peer reviewed.

\section{REFERENCES}

1 Demedts $\mathrm{M}$, Wells AU, Antó JM, et al. Interstitial lung diseases: an epidemiological overview. Eur Respir J Supp/ 2001;32:2s-16s.

2 Raghu G, Chen SY, Yeh WS, et al. Idiopathic pulmonary fibrosis in US Medicare beneficiaries aged 65 years and older: incidence, prevalence, and survival, 2001-11. Lancet Respir Med 2014;2:566-72.

3 King TE Jr, Bradford WZ, Castro-Bernardini S, et al. A phase 3 trial of pirfenidone in patients with idiopathic pulmonary fibrosis. N Engl I Med 2014;370: 2083-92.

4 Richeldi L, du Bois RM, Raghu G, et al. Efficacy and safety of nintedanib in idiopathic pulmonary fibrosis. N Engl J Med 2014;370:2071-82.

5 Nathan SD, Shlobin OA, Weir N, et al. Long-term course and prognosis of idiopathic pulmonary fibrosis in the new millennium. Chest 2011;140: 221-9.
6 Ström K, Boman G. Long-term oxygen therapy in parenchymal lung diseases: an analysis of survival. The Swedish Society of Chest Medicine. Eur Respir J 1993;6:1264-70

7 Hodgson U, Laitinen T, Tukiainen P. Nationwide prevalence of sporadic and familial idiopathic pulmonary fibrosis: evidence of founder effect among multiplex families in Finland. Thorax 2002;57:338-42.

8 Lindell KO, Liang Z, Hoffman LA, et al. Palliative care and location of death in decedents with idiopathic pulmonary fibrosis. Chest 2015;147:423-9.

9 Bajwah S, Higginson IJ, Ross JR, et al. Specialist palliative care is more than drugs: a retrospective study of ILD patients. Lung 2012;190:215-20.

10 Irwin KE, Greer JA, Khatib J, et al. Early palliative care and metastatic non-small cell lung cancer: potential mechanisms of prolonged survival. Chron Respir Dis 2013;10:35-47

11 Gore JM, Brophy CJ, Greenstone MA. How well do we care for patients with end stage chronic obstructive pulmonary disease (COPD)? A comparison of palliative care and quality of life in COPD and lung cancer. Thorax 2000;55:1000-6.

12 Habraken JM, ter Riet G, Gore JM, et al. Health-related quality of life in end-stage COPD and lung cancer patients. J Pain Symptom Manage 2009;37:973-81.

13 Steinhauser KE, Arnold RM, Olsen MK, et al. Comparing three life-limiting diseases: does diagnosis matter or is sick, sick? I Pain Symptom Manage 2011:42:331-41.

14 Bajwah S, Ross JR, Peacock JL, et al. Interventions to improve symptoms and quality of life of patients with fibrotic interstitial lung disease: a systematic review of the literature. Thorax 2013;68:867-79.

15 Bajwah S, Koffman J, Higginson IJ, et al. 'I wish I knew more ...' the end-of-life planning and information needs for end-stage fibrotic interstitial lung disease: views of patients, carers and health professionals. BMJ Support Palliat Care 2013;3:84-90.

16 Bajwah S, Higginson IJ, Ross JR, et al. The palliative care needs for fibrotic interstitial lung disease: a qualitative study of patients, informal caregivers and health professionals. Palliat Med 2013;27:869-76.

17 Gustafson T, Dahlman-Höglund A, Nilsson K, et al. Occupational exposure and severe pulmonary fibrosis. Respir Med 2007;101:2207-12.

18 Ström K, Boe J. A national register for long-term oxygen therapy in chronic hypoxia: preliminary results. Eur Respir J 1988;1:952-8.

19 Swedish National Register for Respiratory Failure (Swedevox). Annual report. 2014. http://www.ucr.uu.se/swedevox/ (accessed 9 Oct 2015)

20 Ekström MP, Bornefalk-Hermansson A, Abernethy AP, et al. Safety of benzodiazepines and opioids in very severe respiratory disease: national prospective study. BMJ 2014;348:g445

21 Ekström MP, Hermansson AB, Ström KE. Effects of cardiovascular drugs on mortality in severe chronic obstructive pulmonary disease. Am J Respir Crit Care Med 2013;187:715-20.

22 Lundström $\mathrm{S}$, Axelsson B, Heedman PA, et al. Developing a national quality register in end-of-life care: the Swedish experience. Palliat Med 2012;26:313-21.

23 Emilsson L, Lindahl B, Köster M, et al. Review of 103 Swedish Healthcare Quality Registries. J Intern Med 2015;277:94-136.

24 The Swedish Register of Palliative Care. http://www.palliativ.se Annual report. 2013. http://palliativ.se/wp-content/uploads/2014/03/SvenskaPalliatvregistret2014.pdf (accessed 1 Sep 2014).

25 Martinsson L, Heedman PA, Lundström S, et al. Validation study of an end-of-life questionnaire from the Swedish Register of Palliative Care. Acta Oncol 2011;50:642-7.

26 Fromme EK, Eilers KM, Mori M, et al. How accurate is clinician reporting of chemotherapy adverse effects? A comparison with patient-reported symptoms from the Quality-of-Life Questionnaire C30. J Clin Oncol 2004;22:3485-90.

27 Basch E, lasonos A, McDonough T, et al. Patient versus clinician symptom reporting using The National Cancer Institute Common Terminology Criteria for Adverse Events: results of a questionnaire-based study. Lancet Oncol 2006;7:903-9.

28 Rocker $\mathrm{G}$, Young J, Donahue $\mathrm{M}$, et al. Perspectives of patients, family caregivers and physicians about the use of opioids for refractory dyspnea in advanced chronic obstructive pulmonary disease. CMAJ 2012;184:E497-504.

29 Young J, Donahue M, Farquhar $\mathrm{M}$, et al. Using opioids to treat dyspnea in advanced COPD: attitudes and experiences of family physicians and respiratory therapists. Can Fam Physician 2012;58:e401-7.

30 Currow DC, Abernethy AP. Therapeutic nihilism: the next hurdle in improving the treatment of breathlessness. Curr Opin Support Palliat Care 2011;5:69-70.

31 Moens K, Higginson IJ, Harding R, EURO IMPACT. Are there differences in the prevalence of palliative care-related problems in people living with advanced cancer and eight non-cancer conditions? A systematic review. J Pain Symptom Manag 2014;48:660-77.

32 Ahmadi Z, Lundström S, Janson C, et al. End-of-life care in oxygen-dependent COPD compared to cancer: a national population-based study. Eur Respir J 2015;46:1190-3.

33 Higginson IJ, Bausewein C, Reilly CC, et al. An integrated palliative and respiratory care service for patients with advanced disease and refractory breathlessness: a randomised controlled trial. Lancet Respir Med 2014;2: $979-87$. 
34 Simon ST, Altfelder N, Alt-Epping B, et al. Is breathlessness what the professional says it is? Analysis of patient and professionals' assessments from a German nationwide register. Support Care Cancer 2014;22: 1825-32.

35 NICE. IPF Quality Standards, section on pallitive care. https://www.nice.org.uk/ guidance/qs79/chapter/Quality-statement-5-Palliative-care (accessed 3 Sep 2015).
36 Bajwah S, Ross JR, Wells AU, et al. Palliative care for patients with advanced fibrotic lung disease: a randomised controlled phase II and feasibility trial of a community case conference intervention. Thorax 2015;70:830-9.

37 Donovan KA, Jacobsen PB. Progress in the implementation of NCCN guidelines for distress management by member institutions. I Nat/ Compr Canc Netw 2013;11:223-6. 